\title{
Preparation of Cerium Modified Titanium Dioxide Nanoparticles and Investigation of Their Visible Light Photocatalytic Performance
}

\author{
Jinfeng Liu, Haiyan Li, Qiuye Li, Xiaodong Wang, Min Zhang, and Jianjun Yang \\ Key Laboratory for Special Functional Materials, Henan University, Kaifeng 475004, China \\ Correspondence should be addressed to Qiuye Li; qiuyeli@henu.edu.cn and Jianjun Yang; yangjianjun@henu.edu.cn
}

Received 4 July 2014; Revised 21 August 2014; Accepted 8 September 2014; Published 1 December 2014

Academic Editor: Wenjun Luo

Copyright (C) 2014 Jinfeng Liu et al. This is an open access article distributed under the Creative Commons Attribution License, which permits unrestricted use, distribution, and reproduction in any medium, provided the original work is properly cited.

Mesoporous $\mathrm{CeO}_{x} / \mathrm{TiO}_{2}$ nanoparticles have been successfully synthesized using titanate nanotubes as precursor through the hydrothermal-calcination method. The as-prepared materials were characterized by means of X-ray diffraction (XRD), X-ray photoelectron spectroscopy (XPS), transmission electron microscope (TEM), UV-vis diffuse reflectance spectra and nitrogen adsorption-desorption isotherm analysis. All the obtained $\mathrm{CeO}_{x} / \mathrm{TiO}_{2}$ materials exhibit anatase phase. Ce element existed in two valance states of $\mathrm{Ce}^{3+}$ and $\mathrm{Ce}^{4+}$. Introduction of Ce species can effectively extend the spectral response from UV to visible light region. $\mathrm{N}_{2}$ adsorption-desorption analysis revealed that all the samples belong to mesoporous structure and have large BET surface area compared with $\mathrm{P} 25$. The $\mathrm{CeO}_{x} / \mathrm{TiO}_{2}$ nanoparticles showed excellent photocatalytic activity in the degradation of MB under visible light irradiation.

\section{Introduction}

$\mathrm{TiO}_{2}$-based materials have been investigated intensively because of their outstanding physical and chemical properties and have been widely used in solar cells, gas sensors, photocatalysis, and other environmentally related applications [16]. However, the low utilization of the sunlight by titanium dioxide limits its practical application. Foreign ions doping is considered to be an effective approach to extend the light response to the visible light region of titanium dioxide [710]. Among these foreign ions, ceria $\left(\mathrm{CeO}_{2}\right)$, as an active system in the photodegradation of several molecules [1113], has been intensively concerned. The redox shift between $\mathrm{CeO}_{2}$ and $\mathrm{Ce}_{2} \mathrm{O}_{3}$ can provide high capacity to store/release oxygen, which plays the role as an oxygen reservoir to exhibit excellent characteristics in transferring electrons. What's more, it also can shift the adsorption band toward to visible light range. Xiao et al. reported that mesoporous cerium doped $\mathrm{TiO}_{2}$ nanofibers exhibited the highest photocatalytic activity under visible irradiation compared with the undoped
$\mathrm{TiO}_{2}$ nanofiber and the commercial Degussa P25 [14]. Xu et al. have reported that cerium doped titania could photocatalytically degrade formaldehyde under visible light [15]. $\mathrm{Li}$ et al. synthesized the ordered mesoporous $\mathrm{CeO}_{2}$ doped $\mathrm{TiO}_{2}$ photocatalyst by an evaporation-induced self-assembly method; their results showed that doping $\mathrm{CeO}_{2}$ species into $\mathrm{TiO}_{2}$ framework not only improves the thermal stability of the ordered mesoporous structure but also effectively extends the photoresponse of $\mathrm{TiO}_{2}$ to the visible light region [16]. Nakamura et al. found that the Ti(IV)-O-Ce(III) bimetallic assemblies on mesoporous silica were an efficient visible light photocatalyst for the photooxidation of 2-propanol [17].

Nanotubes titanate acid (NTA) attracted much attention due to their many excellent properties, such as large BET surface area, strong adsorption capability, ion-exchange capacity, and one-dimensional structure. Recently, Viana et al. synthesized nanotubes titanate acid decorated with $\mathrm{CeO}_{2}$ nanoparticles, and they reported that absorption region redshifted apparently after decorating, and these composites can photodegrade the reactive blue 19 textile dye to a 


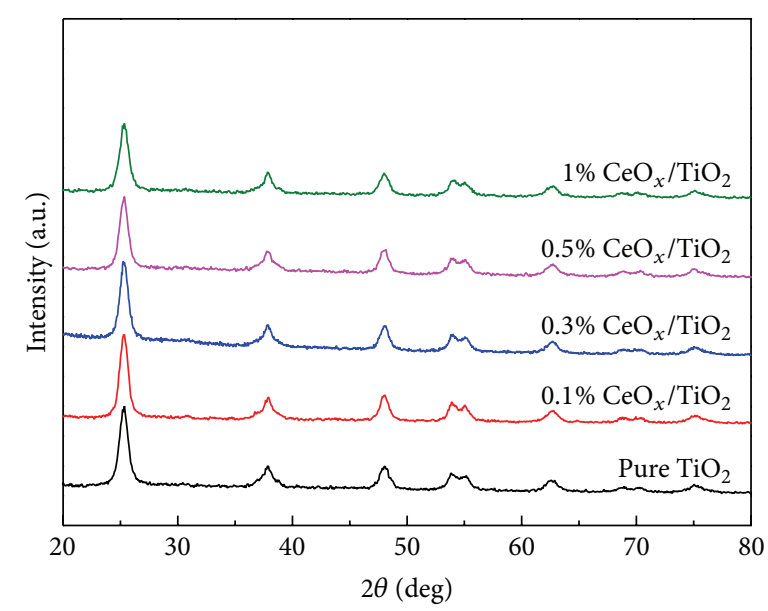

FIGURE 1: XRD patterns of $x \% \mathrm{CeO}_{x} / \mathrm{TiO}_{2}$ nanoparticles obtained from NTA.

certain extent [18]. One of the main researches of our group focuses on the titanate nanotubes and their derivatives. Their morphology, structure, light absorption, thermal stability, formation mechanism, and photoelectrochemical and photocatalytic properties were investigated systematically through decades [19-22]. We found that the crystallinity of NTA was very poor and the photocatalytic activity was not good. However, the crystallinity and photocatalytic performance can be improved largely after thermal dehydration and structure reassemblage of NTA.

In this work, $x \% \mathrm{CeO}_{x} / \mathrm{TiO}_{2}$ was prepared using NTA as the Ti precursor by the hydrothermal-calcination method. The doped $\mathrm{Ce}$ existed in the two valence states of $\mathrm{Ce}^{3+}$ and $\mathrm{Ce}^{4+}$, which can act as the electron acceptor to improve the separation efficiency of the photogenerated electronhole pairs. Moreover, the absorption of the visible light extended more apparently than that of the reference $\mathrm{TiO}_{2}$. The photodegradation yield of $\mathrm{MB}$ on $\mathrm{CeO}_{x} / \mathrm{TiO}_{2}$ was much higher than the commercial P25. The relationship between the morphology, structure, light absorption, and the photocatalytic performance was investigated in detail.

\section{Experimental}

2.1. Preparation of $\mathrm{CeO}_{x} / \mathrm{TiO}_{2}$. The titania precursor of nanotubular titanic acid (NTA) was prepared according to our previous reports [23]. A proper amount of $\mathrm{Ce}\left(\mathrm{NO}_{3}\right)_{3}$ and $1 \mathrm{~g}$ of NTA were dissolved in $60 \mathrm{~mL}$ of deionized water and mixed by stirring. Then the resultant mixed suspension was transferred to the autoclave reactor and kept at $120^{\circ} \mathrm{C}$ for $4 \mathrm{~h}$. The resultant mixture was transferred to a round bottom flask to evaporate water by a vacuum distillation and then the production was calcined at $400^{\circ} \mathrm{C}$ for $2 \mathrm{~h}$. And as a result, the $\mathrm{CeO}_{x} / \mathrm{TiO}_{2}$ was obtained. The atomic ratio of $\mathrm{Ce}$ and $\mathrm{Ti}$ was designed as $0.1 \%, 0.3 \%, 0.5 \%$, and $1 \%$, and the samples were denoted as $x \% \mathrm{CeO}_{x} / \mathrm{TiO}_{2}$.

2.2. Characterization. The phase structure of various $\mathrm{CeO}_{x} / \mathrm{TiO}_{2}$ samples was analyzed by X-ray diffraction (XRD,
Philips X'Pert Pro X-ray diffractometer; $\mathrm{Cu}-\mathrm{K} \alpha$ radiation, $\lambda=0.15 \mathrm{~nm}$ ). The X-ray photoelectron spectroscopic (XPS) measurement was carried out using ESCALAB210 with dual anode Mg X-ray source. All spectra were calibrated to the binding energy of the adventitious C $1 \mathrm{~s}$ peak at $285 \mathrm{eV}$. All samples were observed using a transmission electron microscopy (TEM, JEOL JEM-2100, accelerating voltage $200 \mathrm{kV}$ ). UV-vis diffuse reflectance spectra (DRS) were obtained on a Shimadzu U-3010 spectrometer, using $\mathrm{BaSO}_{4}$ as a reference. The Brunauer-Emmett-Teller (BET) surface areas and average pore volumes were measured by automatic surface area and porosity analyzer (QUADRASORB SI).

2.3. Photocatalytic Reaction. The photocatalytic activity of each sample was evaluated in terms of the degradation of $\mathrm{MB}(10 \mathrm{mg} / \mathrm{L}) .0 .1 \mathrm{~g}$ of photocatalyst was added into a $100 \mathrm{~mL}$ quartz photochemical reactor containing $100 \mathrm{~mL}$ of $\mathrm{MB}(10 \mathrm{mg} / \mathrm{L})$ aqueous solution. The mixture was stirred for $1.5 \mathrm{~h}$ in dark to reach the adsorption-desorption equilibrium. A $300 \mathrm{~W}$ Xe lamp equipped with a UV cut-off filter $(\lambda>$ $420 \mathrm{~nm}$ ) was used as a visible light source. At given time intervals, the analytical samples were taken from the mixture and immediately centrifuged and then filtered to remove the particles. The concentration of MB was analyzed by checking the absorbance at $664 \mathrm{~nm}$ with a UV-vis spectrophotometer (UV-2500, Shimadzu, Japan). The photocatalytic behavior of Degussa P25 was also measured in the same conditions as a reference. The 4-chlorophenol (4-CP, $12 \mathrm{mg} / \mathrm{L})$ was also selected as the colorless model pollutant to further evaluate the photocatalytic activity.

\section{Results and Discussions}

The XRD patterns of the series of $\mathrm{CeO}_{x} / \mathrm{TiO}_{2}$ samples with different content of $\mathrm{Ce}$ are shown in Figure 1. All of these $\mathrm{CeO}_{x} / \mathrm{TiO}_{2}$ samples show the typical anatase crystal phase; the typical diffraction peaks at $25.3^{\circ}, 37.8^{\circ}, 48.0^{\circ}, 53.9^{\circ}$, $55.0^{\circ}$, and $62.7^{\circ}$ corresponded to the (101), (104), (200), (105), (211), and (204) plane facet, respectively. Our previous 


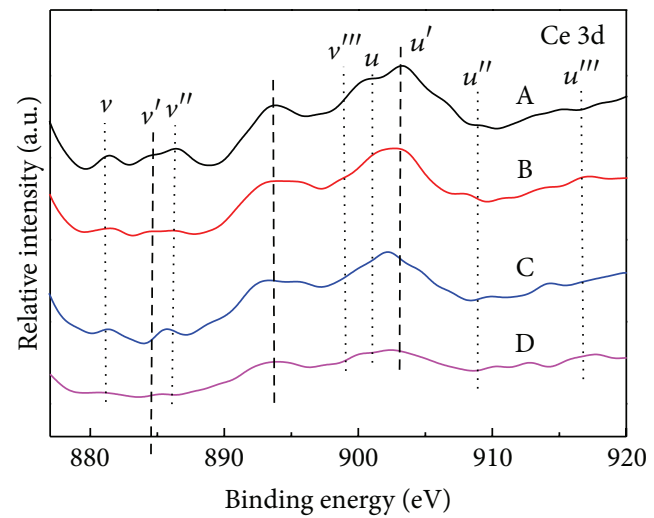

(a)

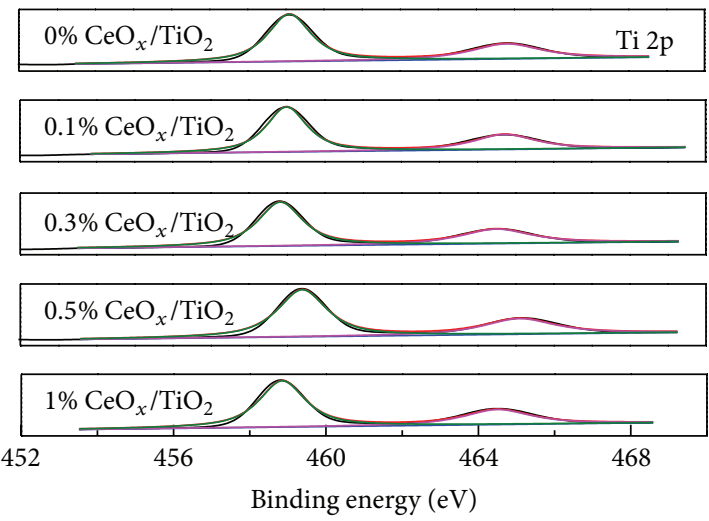

(b)
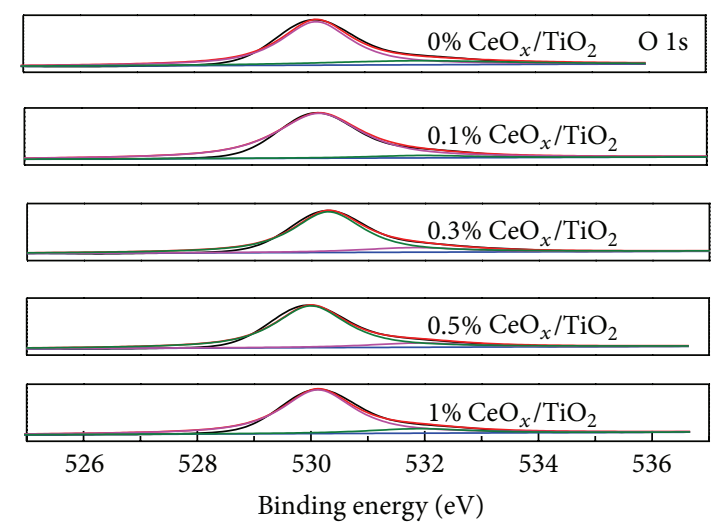

(c)

Figure 2: XPS spectra of $x \% \mathrm{CeO}_{x} / \mathrm{TiO}_{2}$ nanoparticles (a) Ce 3d: (A) $1 \% \mathrm{CeO}_{x} / \mathrm{TiO}_{2}$, (B) $0.5 \% \mathrm{CeO}_{x} / \mathrm{TiO}_{2},(\mathrm{C}) 0.3 \% \mathrm{CeO}_{x} / \mathrm{TiO}{ }_{2}$, and (D) $0.1 \% \mathrm{CeO}_{x} / \mathrm{TiO}_{2}$; (b) $\mathrm{Ti} 2 \mathrm{p}$; (c) $\mathrm{O} 1 \mathrm{~s}$.

work has reported that NTA belongs to an orthorhombic crystallinity [21]. From the above XRD results, we knew that NTA had been transformed to anatase $\mathrm{TiO}_{2}$ completely through the hydrothermal-calcination process. The anatase peaks position of all samples undergoes almost no significant changes; this may be because the ionic radii of $\mathrm{Ce}^{3+} / \mathrm{Ce}^{4+}$ $(1.03 / 1.02 \AA)$ are much bigger than that of $\mathrm{Ti}^{4+}(0.68 \AA)$, so it is difficult for $\mathrm{Ce}^{3+}$ or $\mathrm{Ce}^{4+}$ to replace $\mathrm{Ti}^{4+}$ in the crystal lattice [14]. Thus, we inferred that cerium species should be in the form of cerium oxide modified on the surface of $\mathrm{TiO}_{2}$. However, the intensive peaks of all kinds of cerium species $\left(\mathrm{CeO}_{2} / \mathrm{Ce}_{2} \mathrm{O}_{3}\right)$ cannot be identified in XRD patterns. This should be due to the small content of cerium oxide species to be detected. Through calculation by the Scherrer formula, the particle sizes of $\mathrm{CeO}_{x} / \mathrm{TiO}_{2}$ are ca. $8-12 \mathrm{~nm}$ and there is no apparent difference between the samples with different content of Ce.

XPS analysis was conducted to understand the surface chemical state of $\mathrm{Ce}$ and $\mathrm{Ti}$ in the $\mathrm{CeO}_{x} / \mathrm{TiO}_{2}$ nanoparticles. The spectra of Ce $3 \mathrm{~d}$ are shown in Figure 2(a). The spectra of $\mathrm{Ce} 3 \mathrm{~d}$ are rather complex because of the hybridization of $\mathrm{Ce}$ $3 \mathrm{~d}$ and Ti $2 \mathrm{p}$ orbitals and splitting of the peaks [24]. The labels $\mathrm{v}$ and $\mathrm{u}$ indicate Ce $3 \mathrm{~d}_{5 / 2}$ and $3 \mathrm{~d}_{3 / 2}$, respectively. According to the previous reports, $\mathrm{u}^{\prime \prime \prime} / \mathrm{v}^{\prime \prime \prime}$ doublet is due to the primary photoemission from $\mathrm{Ce}^{4+}-\mathrm{O}_{2}$, and $\mathrm{v} / \mathrm{u}$ and $\mathrm{v}^{\prime \prime} / \mathrm{u}^{\prime \prime}$ doublets are resulting from the transfer of one or two electrons from a filled O $2 \mathrm{p}$ orbital to an empty Ce 4 f orbital. $\mathrm{v}^{\prime} / \mathrm{u}^{\prime}$ doublet is due to photoemission from $\mathrm{Ce}^{3+}$ cations $[25,26]$. The broad peak around $894.4 \mathrm{eV}$ also indicates the presence of $\mathrm{Ce}^{3+}$ [24]. Therefore, the mixture of $\mathrm{Ce}^{3+} / \mathrm{Ce}^{4+}$ oxidation states exists on the surface of $\mathrm{TiO}_{2}$ nanoparticles, which exhibited excellent characteristics in transferring charge carriers. The binding energies of $\mathrm{Ti} 2 \mathrm{p}_{1 / 2}$ and $2 \mathrm{p}_{3 / 2}$ in $\mathrm{CeO}_{x} / \mathrm{TiO}_{2}$ are shown in Figure 2(b). All binding energy values are about $464.4 \mathrm{eV}$ and $485.8 \mathrm{eV}$, indicating that the cations exist in the form of $\mathrm{Ti}^{4+}$ [27]. With the increasing of Ce content, the $\mathrm{Ti} 2 \mathrm{p}$ binding energies do not change much. The binding energy of $\mathrm{Ti}^{3+}$ is lower than that of $\mathrm{Ti}^{4+}$ about $1.8 \mathrm{eV}$ [28], which is not observed in the Ti $2 \mathrm{p}$ XPS spectra of the $\mathrm{CeO}_{x} / \mathrm{TiO}_{2}$ nanoparticles. The XPS spectra of $\mathrm{O} 1 \mathrm{~s}$ are shown in Figure 2(c). The two peak values indicate that at least two kinds of oxygen species are present at the surface. The stronger peak about $529.6 \mathrm{eV}$ is a characteristic peak of the metal oxide (Ti-O), while the wide peak about $532 \mathrm{eV}$ can attribute to surface hydroxyl groups (Ti-OH) $[29,30]$. The cerium content obtained by EDX in $\mathrm{CeO}_{x} / \mathrm{TiO}_{2}$ nanoparticles is 


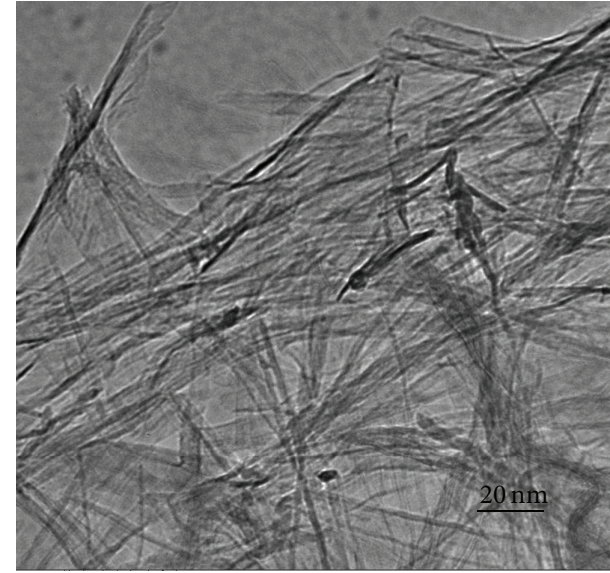

(a)

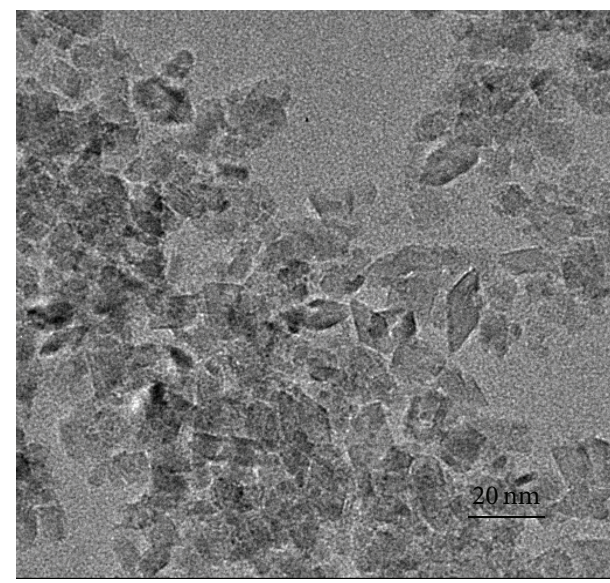

(c)

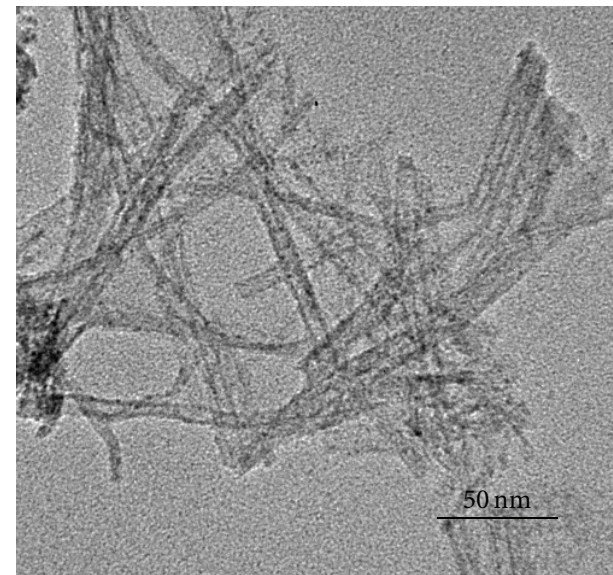

(b)

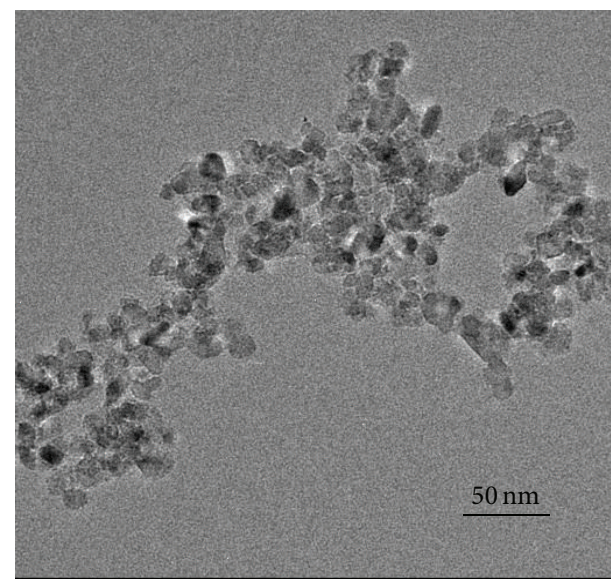

(d)

Figure 3: TEM images of (a) NTA; (b) NTA ion-exchanged with $\mathrm{Ce}\left(\mathrm{NO}_{3}\right)_{3}$; (c) $0.1 \% \mathrm{CeO}_{x} / \mathrm{TiO}_{2}$ nanoparticles after hydrothermal method; (d) $0.1 \% \mathrm{CeO}_{x} / \mathrm{TiO}_{2}$ nanoparticles after calcination.

listed in Table 1. With the increasing of the theory content, the actual measured content increased, and theoretical content is greater than the actual measured content; this may be due to the loss during the experiment.

The structural and morphological study was completed with the help of transmission electron microscopy technique. As shown in Figure 3, NTA displays uniform nanotube structure, the diameters of NTA are about $6-10 \mathrm{~nm}$, and the surface of the nanotubes was much more smooth. Figure 3(b) indicated that the nanotubular morphology was kept after NTA was ion-exchanged with $\mathrm{Ce}\left(\mathrm{NO}_{3}\right)_{3}$, but some small particles were modified on the surface of NTA. After hydrothermal process, the nanotubular morphology transformed to octahedron, as shown in Figure 3(c). And the particle sizes increase and the octahedron changed to irregular particles after calcination at $400^{\circ} \mathrm{C}$ for $2 \mathrm{~h}$. The formation process of $\mathrm{CeO}_{x} / \mathrm{TiO}_{2}$ nanoparticles from NTA was illustrated iconically in Figure 4.

The UV-vis DRS of the as-prepared $\mathrm{CeO}_{x} / \mathrm{TiO}_{2}$ nanoparticles and the Degussa P25 reference are shown in Figure 5(a). By the increasing content of ceria, the UV-vis DRS of the $\mathrm{CeO}_{x} / \mathrm{TiO}_{2}$ nanoparticles are significantly shifted toward visible light as compared with that of P25. We have obtained a similar result with several researches. They reported that there would have a continuous increase of absorption in the visible region (going from ca. 380 to $500 \mathrm{~nm}$ ) with increasing ceria content of the material [12, 31, 32]. Seen from our experimental results, the absorbance edge of the $\mathrm{CeO}_{x} / \mathrm{TiO}_{2}$ is shifted to high wavelength when the molar ratio of $\mathrm{Ce} / \mathrm{Ti}$ is increased from $0 \mathrm{wt} \%$ to $1 \mathrm{wt} \%$, which drives an apparent modification of the band gap. The band gap energy (Eg) was calculated from the UV absorption spectra taking into account that $\alpha(E) \infty(E-E g)^{m / 2}$, where $\alpha(E)$ is the absorption coefficient for a photon of energy $E$ and $m=1$ for an indirect transition between bands [33]. The band gap energy is presented in Figure 5(b). This indicated that the hydrothermal-calcination method can effectively improve the optical properties.

The pore structure and surface areas of all samples are investigated by $\mathrm{N}_{2}$ adsorption-desorption isotherm. As can be seen from Figure 6(a), all of these samples show isotherms of type IV, indicating the mesoporous structure of samples. 
TABLE 1: Effect of surface area, pore diameter, pore volume and cerium atom content of $\mathrm{CeO}_{x} / \mathrm{TiO}_{2}$ nanoparticles.

\begin{tabular}{lcccc}
\hline Sample & $\begin{array}{c}\text { BET surface area } \\
\left(\mathrm{m}^{2} / \mathrm{g}\right)\end{array}$ & $\begin{array}{c}\text { Pore diameter } \\
(\mathrm{nm})\end{array}$ & $\begin{array}{c}\text { Pore volume } \\
\left(\mathrm{cm}^{3} / \mathrm{g}\right)\end{array}$ & $\begin{array}{c}\text { Cerium atom content } \\
(\%)\end{array}$ \\
\hline $\mathrm{P} 25$ & 54.89 & 15.22 & 0.27 & - \\
$0.1 \% \mathrm{CeO}_{x} / \mathrm{TiO}_{2}$ & 120.92 & 3.88 & 0.31 & $0.11 \%$ \\
$0.3 \% \mathrm{CeO}_{x} / \mathrm{TiO}_{2}$ & 133.86 & 3.88 & 0.33 & $0.17 \%$ \\
$0.5 \% \mathrm{CeO}_{x} / \mathrm{TiO}_{2}$ & 139.35 & 3.90 & 0.38 & $0.39 \%$ \\
$1 \% \mathrm{CeO}_{x} / \mathrm{TiO}_{2}$ & 137.22 & 3.88 & 0.34 & $0.77 \%$ \\
\hline
\end{tabular}

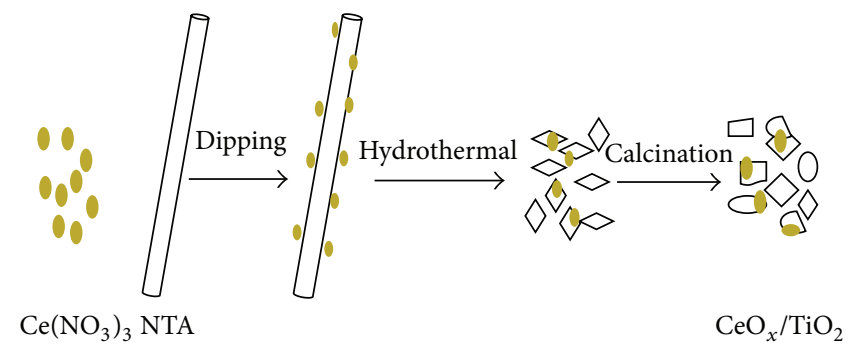

Figure 4: Formation schematic diagram of $\mathrm{CeO}_{x} / \mathrm{TiO}_{2}$ nanoparticles.

The corresponding hysteresis loops are type $\mathrm{H} 3$ at a high relative pressure range of $0.75-1.0$, suggesting the presence of slit-like pores $[34,35]$. The generation of hysteresis loops is from the aggregation of the sheet-like $\mathrm{TiO}_{2}$ nanoparticles. This result is also consistent with TEM images. In Figure 6(b), the pore distribution of $0.1 \%$ to $1 \% \mathrm{CeO}_{x} / \mathrm{TiO}_{2}$ is in the range of 2-6 $\mathrm{nm}$. The detailed BET surface area and pore volume for these samples are shown in Table 1 . The series of $\mathrm{CeO}_{x} / \mathrm{TiO}_{2}$ nanoparticles prepared by NTA as precursor have large surface areas, which range from 120 to $137 \mathrm{~m}^{2} \mathrm{~g}^{-1}$, while P25 only has $54 \mathrm{~m}^{2} \mathrm{~g}^{-1}$. These large surface areas could provide much more adsorption sites for pollutant molecules, which is advantageous for improving the photocatalytic activity of the samples.

Photodegradation of MB was used as the probe reaction to evaluate the photocatalytic activity of samples under visible light irradiation (Figure 7(a)). All the $\mathrm{CeO}_{x} / \mathrm{TiO}_{2}$ samples showed relatively higher activities as compared with P25. The reason for this result may have three points as follows. The first one is that the samples prepared by NTA as precursor have relative larger BET surface area. This can have much more adsorption sites for MB on the sample surface. The second is $\mathrm{CeO}_{x}$, which enhanced the visible absorption of the samples. And the last one is Ce element existing as a mixture of $\mathrm{Ce}^{3+} / \mathrm{Ce}^{4+}$ oxidation states, which can act as the electron acceptor for the photogenerated charge carriers, thereby improving the separation efficiency of the electronhole pair. In particular, $0.1 \% \mathrm{CeO}_{x} / \mathrm{TiO}_{2}$ exhibits the best photocatalytic activity, having a photodegradation yield of ca. $68 \%$ for $\mathrm{MB}$ dye. The stability of $0.1 \% \mathrm{CeO}_{x} / \mathrm{TiO}_{2}$ on the photodegradation reaction was investigated. As shown in Figure $7(\mathrm{~b})$, the degradation yield of $\mathrm{MB}$ on $0.1 \% \mathrm{CeO}_{x} / \mathrm{TiO}_{2}$ had no significant difference in the consecutive three cycles. Therefore, $0.1 \% \mathrm{CeO}_{x} / \mathrm{TiO}_{2}$ showed a very good stability in the degradation of MB.
With the increase of the doping amount with $\mathrm{Ce}$, the photodegradation yield of MB decreased. In order to clarify the reasons for this result, the active species in photodegradation process of $\mathrm{MB}$ were detected. Methanol and silver nitrate solution were added into $\mathrm{MB}$ dyes solution to capture electrons and holes, respectively. As can be seen from Figure $7(\mathrm{c})$, the degradation yield of MB decreased to a certain extent when the electrons or holes were captured. And more significant change of activity decreased largely when the electrons were eliminated. So we speculated that both electrons and holes are involved in the photocatalytic degradation of $\mathrm{MB}$ dyes, and the contributions of electrons are larger than that of holes.

Based on the above experimental results, a possible mechanism for $\mathrm{MB}$ degradation on $\mathrm{CeO}_{x} / \mathrm{TiO}_{2}$ samples was proposed in Figure 8. Under visible light irradiation, the electrons can be excited from the valence band (VB) of Ce modified titania samples into conduction band (CB) and holes are left in the valence band. Ce element existed as a mixture of $\mathrm{Ce}^{3+} / \mathrm{Ce}^{4+}$ oxidation states. The $\mathrm{Ce}^{4+}$ can act as the electron acceptor for the photogenerated charge carriers. So, the separation efficiency of the electron-hole pair can be improved. For the pure titania, both electrons and holes participate in photodegradation of $\mathrm{MB}$ organic pollutants. The excited electrons react with the adsorbed oxygen to form oxidizing species. MB was mineralized into carbon dioxide and water by the oxidizing species as well as holes. While part of the excited electrons would be trapped by Ce $4 \mathrm{f}$ orbitals, and cannot participate in the photocatalytic reaction. And the others not trapped by $\mathrm{Ce}$ and the holes would participate in the photocatalytic reaction (as shown in Figure 8); we come to the conclusion that the electrons play a predominance role in the progress of photodegradation of $\mathrm{MB}$ organic pollutants. So the electrons trapped by $\mathrm{Ce} 4 \mathrm{f}$ orbitals decrease the photocatalytic activity. 

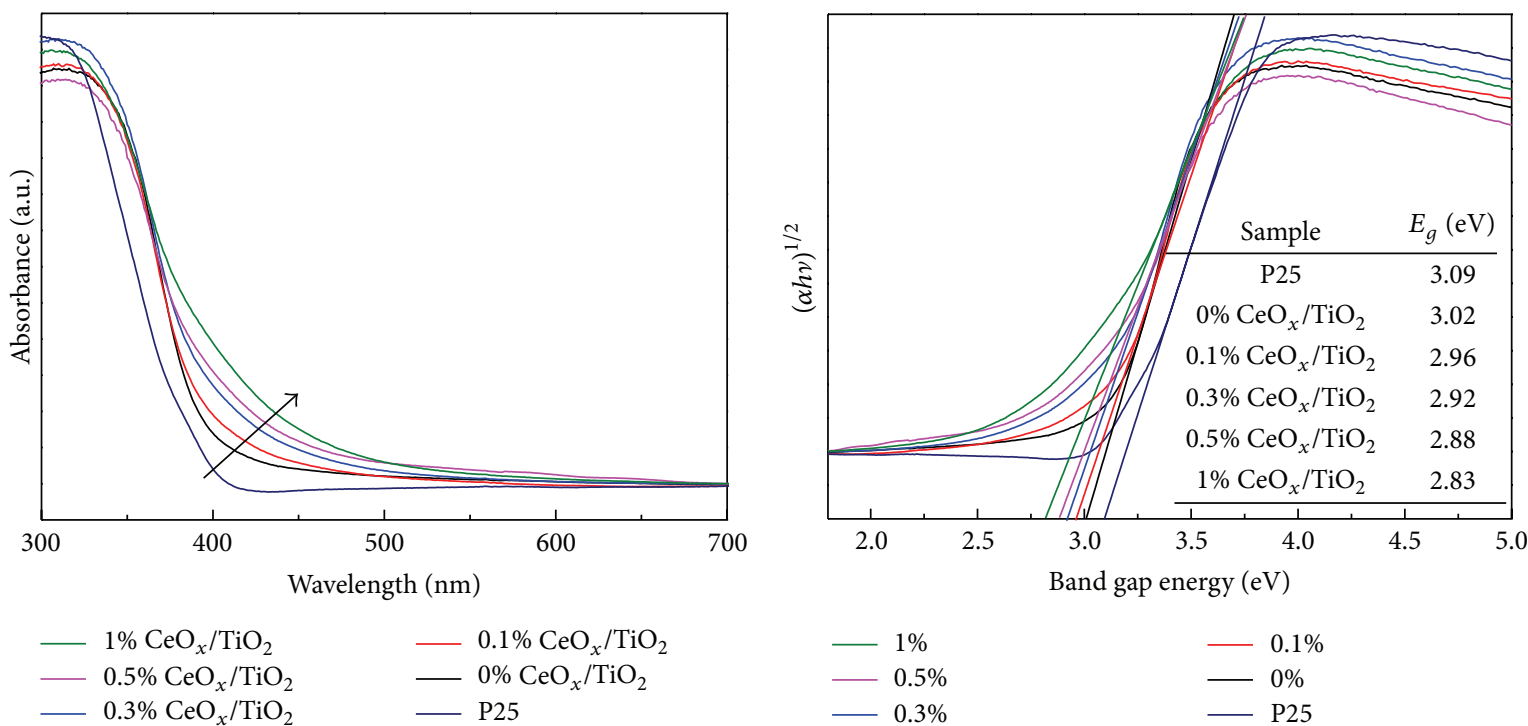

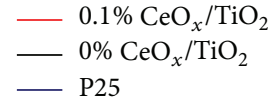

(a)

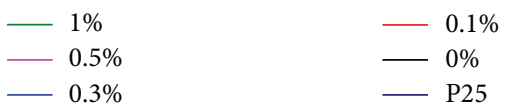

(b)

Figure 5: (a) UV-vis DRS of $\mathrm{P} 25$ and the $x \% \mathrm{CeO}_{x} / \mathrm{TiO}_{2}$ nanoparticles; (b) the plot of band gap energy and $(\alpha h \nu)^{1 / 2}$ of $\mathrm{P}_{25}$ and $\mathrm{CeO}_{x} / \mathrm{TiO}_{2}$ nanoparticles.

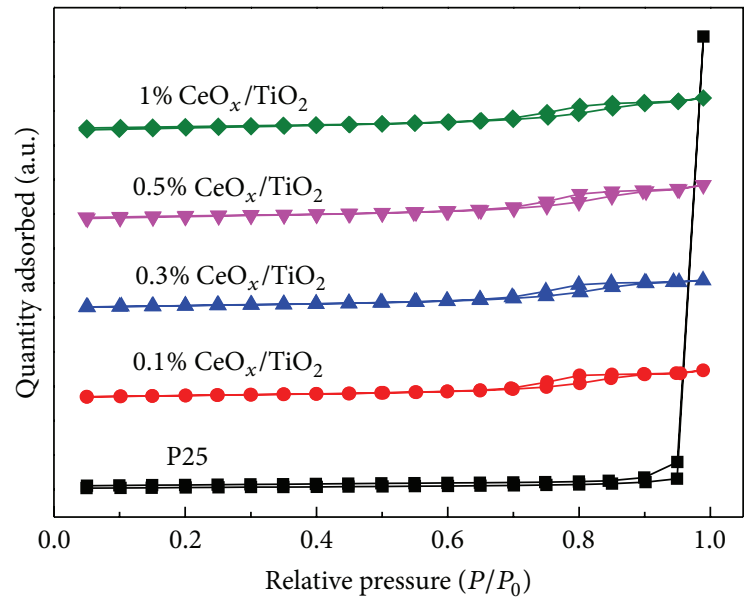

(a)

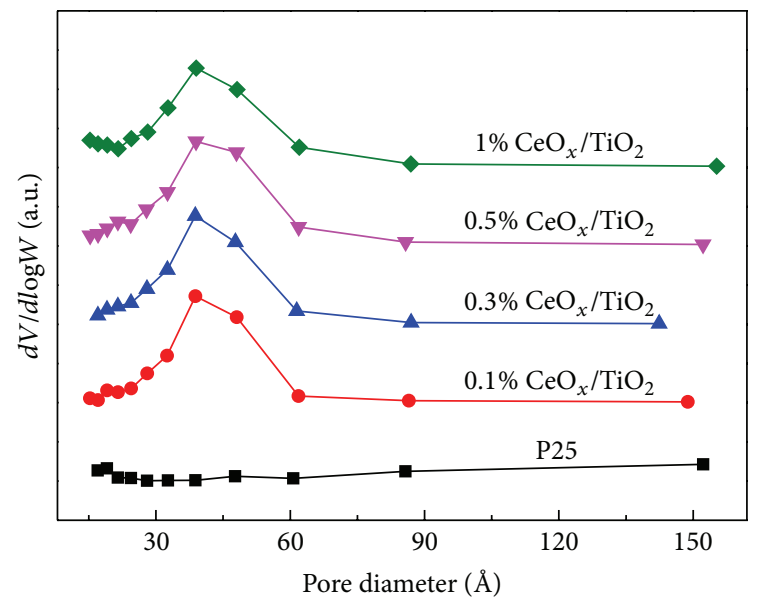

(b)

Figure 6: (a) Nitrogen adsorption-desorption isotherms of $\mathrm{P} 25$ and $x \% \mathrm{CeO}_{x} / \mathrm{TiO}_{2}$ nanoparticles; (b) BJH pore-size distributions of $\mathrm{P} 25$ and $x \% \mathrm{CeO}_{x} / \mathrm{TiO}_{2}$ nanoparticles.

Besides MB, the colorless 4-chlorophenol (4-CP) was also selected as a model pollutant. The results were shown in Figure 7(d). Compared with $\mathrm{P} 25,0.1 \% \mathrm{CeO}_{x} / \mathrm{TiO}_{2}$ showed much higher photocatalytic activity after irradiating for $6 \mathrm{~h}$. The photodegradation yield of $4-\mathrm{CP}$ on $0.1 \% \mathrm{CeO}_{x} / \mathrm{TiO}_{2}$ reached ca. $79 \%$, while the degradation yield on P25 was only $40 \%$.

\section{Conclusions}

Mesostructured $\mathrm{CeO}_{x} / \mathrm{TiO}_{2}$ nanoparticles with different Ce contents have been successfully synthesized using titanate nanotubes as precursor by hydrothermal-calcination method. Fine-crystallized $\mathrm{CeO}_{x} / \mathrm{TiO}_{2}$ could be obtained and crystal size was about $8-12 \mathrm{~nm}$. And the Ce did not incorporate into the lattice of $\mathrm{TiO}_{2}$, which just existed as the cerium oxide modified on the surface of $\mathrm{TiO}_{2}$. XPS results indicated that $\mathrm{Ce}$ species were in the form of $\mathrm{Ce}^{3+}$ and $\mathrm{Ce}^{4+}$. TEM images presented that the NTA nanotubes have transformed to $\mathrm{TiO}_{2}$ nanoparticles completely. Introduction of Ce species can effectively extend the spectral response from UV to visible area of $\mathrm{TiO}_{2} . \mathrm{N}_{2}$ adsorption-desorption analysis revealed that all the samples belonged to mesoporous structure and had large surface area. All the $\mathrm{CeO}_{x} / \mathrm{TiO}_{2}$ nanoparticles showed much higher photocatalytic activity compared with P25 in the degradation of MB aqueous 


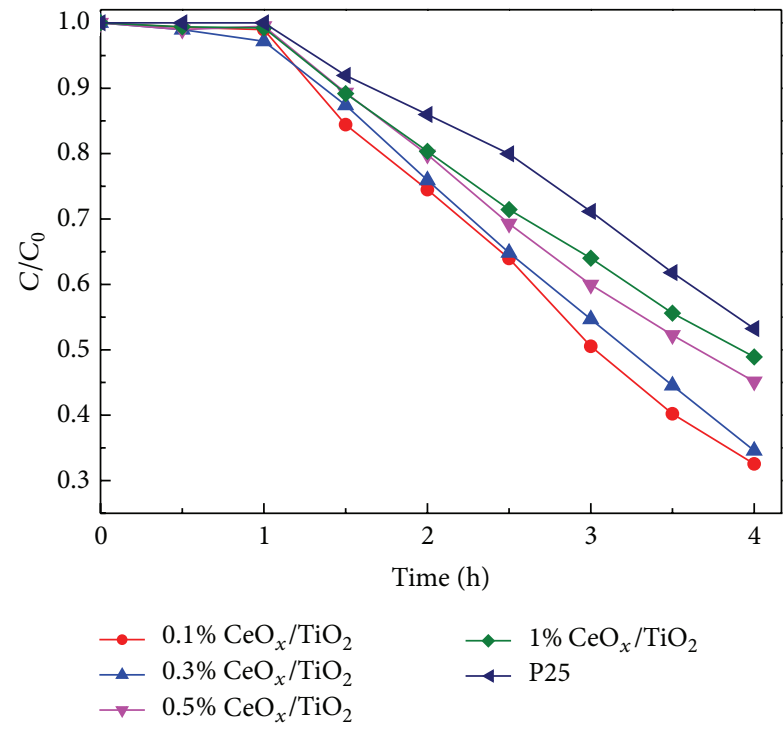

(a)

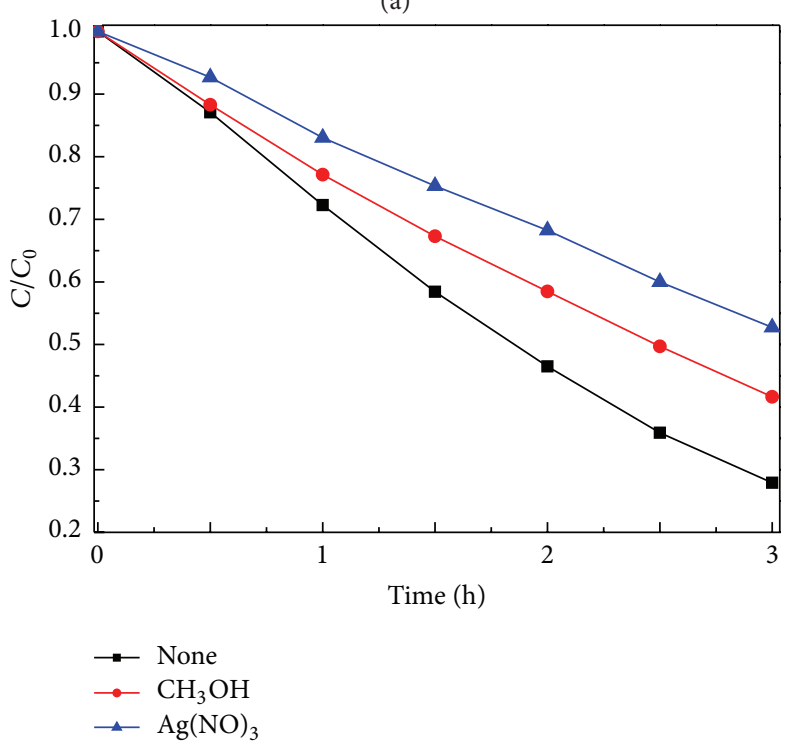

(c)

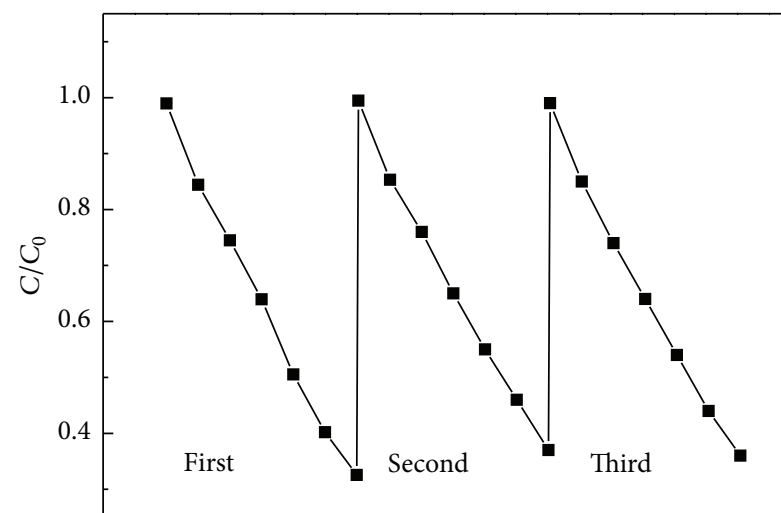

(b)

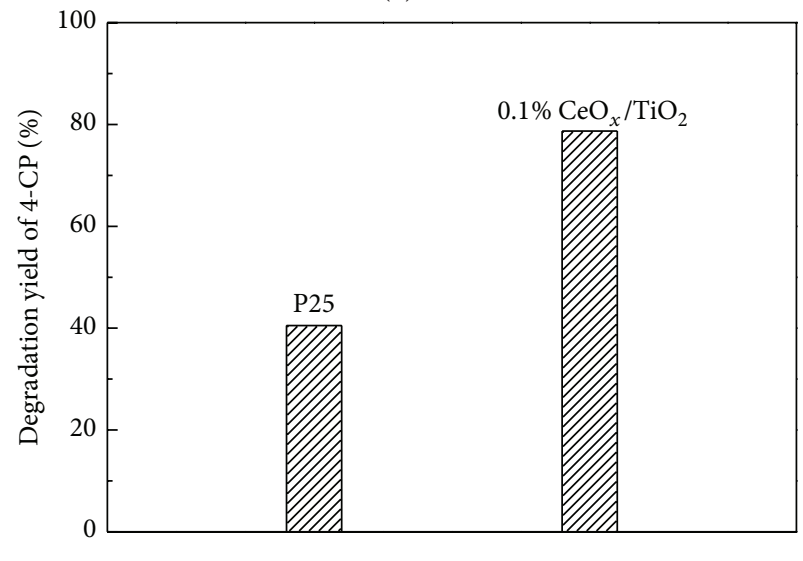

Figure 7: Photocatalytic activity for $\mathrm{MB}$ (a) and stability (b) of P25 and $x \% \mathrm{CeO}_{x} / \mathrm{TiO}_{2}$ nanoparticles; (c) detection of the active species of electrons and holes; (d) photocatalytic degradation yield of 4 -CP on $\mathrm{P} 25$ and $0.1 \% \mathrm{CeO}_{x} / \mathrm{TiO}_{2}$ nanoparticles.

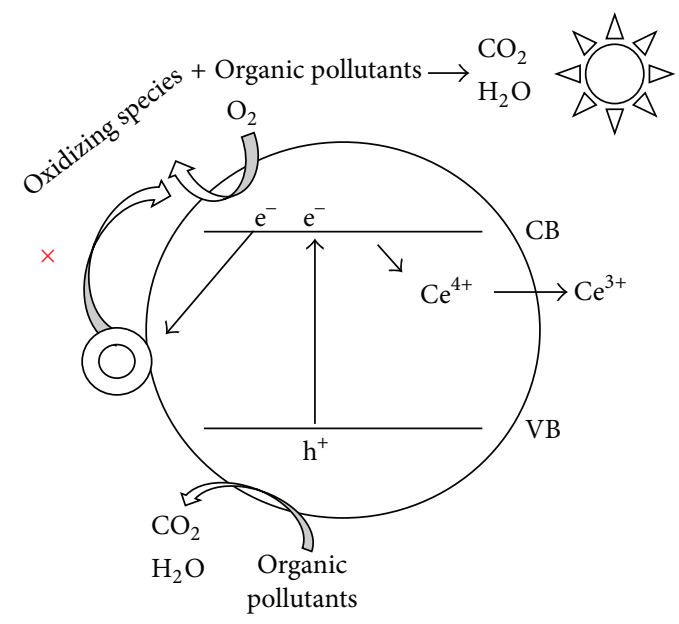

FIgURE 8: The proposed photocatalytic mechanism of $\mathrm{CeO}_{x} / \mathrm{TiO}_{2}$ nanoparticles for the degradation of MB under visible light. 
solution under the visible irradiation, especially for the $0.1 \% \mathrm{CeO}_{x} / \mathrm{TiO}_{2}$ samples. As the Ce content increases, the degradation yield of $\mathrm{MB}$ decreased gradually, which should be due to the capture of electrons by $\mathrm{Ce}^{4+}$.

\section{Conflict of Interests}

The authors declare that there is no conflict of interests regarding the publication of this paper.

\section{Acknowledgments}

The authors gratefully acknowledge the support of the National Natural Science Foundation of China (nos. 21103042, 21471047, 20973054, and 21203054), Program for Changjiang Scholars and Innovation Research Team in University (no. PCS IRT1126), and the Specialized Research Fund for the Doctoral Program of Higher Education (no. 20114103120001).

\section{References}

[1] J. Zhang, Z. Zhao, X. Wang et al., "Increasing the oxygen vacancy density on the $\mathrm{TiO}_{2}$ surface by La-doping for dyesensitized solar cells," The Journal of Physical Chemistry C, vol. 114, no. 43, pp. 18396-18400, 2010.

[2] W. Tu, Y. Zhou, Q. Liu et al., "An in situ simultaneous reductionhydrolysis technique for fabrication of $\mathrm{TiO}_{2}$-graphene $2 \mathrm{D}$ sandwich-like hybrid nanosheets: graphene-promoted selectivity of photocatalytic-driven hydrogenation and coupling of $\mathrm{CO}_{2}$ into methane and ethane," Advanced Functional Materials, vol. 23, no. 14, pp. 1743-1749, 2013.

[3] T. L. Thompson and J. T. Yates Jr., "Surface science studies of the photoactivation of $\mathrm{TIO}_{2}$ - new photochemical processes," Chemical Reviews, vol. 106, no. 10, pp. 4428-4453, 2006.

[4] X. Chen and S. S. Mao, "Titanium dioxide nanomaterials: synthesis, properties, modifications and applications," Chemical Reviews, vol. 107, no. 7, pp. 2891-2959, 2007.

[5] G. Dagan and M. Tomkiewicz, "Titanium dioxide aerogels for photocatalytic decontamination of aquatic environments," Journal of Physical Chemistry, vol. 97, no. 49, pp. 12651-12655, 1993.

[6] Z. G. Zou, J. H. Ye, K. Sayama, and H. Arakawa, "Direct splitting of water under visible light irradiation with an oxide semiconductor photocatalyst," Nature, vol. 414, no. 6864, pp. 625-627, 2001.

[7] Y. Cao, T. He, L. Zhao, E. Wang, and W. Yang, "Structure and phase transition behavior of $\mathrm{sn}^{4+}$-doped $\mathrm{TiO}_{2}$ nanoparticles," Journal of Physical Chemistry C, vol. 113, no. 42, pp. 18121-18124, 2009.

[8] J. Zhu, W. Zheng, B. He, J. Zhang, and M. Anpo, "Characterization of $\mathrm{Fe}-\mathrm{TiO}_{2}$ photocatalysts synthesized by hydrothermal method and their photocatalytic reactivity for photodegradation of XRG dye diluted in water," Journal of Molecular Catalysis A: Chemical, vol. 216, no. 1, pp. 35-43, 2004.

[9] M. A. Debeila, N. J. Coville, M. S. Scurrell, and G. R. Hearne, "The effect of calcination temperature on the adsorption of nitric oxide on $\mathrm{Au}_{-}-\mathrm{TiO}_{2}$ : drifts studies," Applied Catalysis A: General, vol. 291, no. 1-2, pp. 98-115, 2005.
[10] W. Ren, Z. Ai, F. Jia, L. Zhang, X. Fan, and Z. Zou, "Low temperature preparation and visible light photocatalytic activity of mesoporous carbon-doped crystalline $\mathrm{TiO}_{2}$," Applied Catalysis B: Environmental, vol. 69, no. 3-4, pp. 138-144, 2007.

[11] M. D. Hernández-Alonso, A. B. Hungría, A. Martínez-Arias et al., "Confinement effects in quasi-stoichiometric $\mathrm{CeO}_{2}$ nanoparticles," Physical Chemistry Chemical Physics, vol. 6, no. 13, pp. 3524-3529, 2004.

[12] P. Ji, J. Zhang, F. Chen, and M. Anpo, "Study of adsorption and degradation of acid orange 7 on the surface of $\mathrm{CeO}_{2}$ under visible light irradiation," Applied Catalysis B: Environmental, vol. 85, no. 3-4, pp. 148-154, 2009.

[13] M. D. Hernández-Alonso, A. B. Hungría, A. Martínez-Arias et al., "EPR study of the photoassisted formation of radicals on $\mathrm{CeO}_{2}$ nanoparticles employed for toluene photooxidation," Applied Catalysis B: Environmental, vol. 50, no. 3, pp. 167-175, 2004.

[14] G. Xiao, X. Huang, X. P. Liao, and B. Shi, "One-pot facile synthesis of cerium-doped $\mathrm{TiO}_{2}$ mesoporous nanofibers using collagen fiber as the biotemplate and its application in visible light photocatalysis," Journal of Physical Chemistry C, vol. 117, no. 19, pp. 9739-9746, 2013.

[15] Y. H. Xu, H. R. Chen, Z. X. Zeng, and B. Lei, "Investigation on mechanism of photocatalytic activity enhancement of nanometer cerium-doped titania," Applied Surface Science, vol. 252, no. 24, pp. 8565-8570, 2006.

[16] G. Li, D. Zhang, and J. C. Yu, "Thermally stable ordered mesoporous $\mathrm{CeO}_{2} / \mathrm{TiO}_{2}$ visible-light photocatalysts," Physical Chemistry Chemical Physics, vol. 11, no. 19, pp. 3775-3782, 2009.

[17] R. Nakamura, A. Okamoto, H. Osawa, H. Irie, and K. Hashimoto, "Design of all-inorganic molecular-based photocatalysts sensitive to visible light: $\mathrm{Ti}(\mathrm{IV})-\mathrm{O}-\mathrm{Ce}(\mathrm{III})$ bimetallic assemblies on mesoporous silica," Journal of the American Chemical Society, vol. 129, no. 31, pp. 9596-9597, 2007.

[18] B. C. Viana, O. P. Ferreira, A. G. Souza Filho et al., "Decorating titanate nanotubes with $\mathrm{CeO}_{2}$ nanoparticles," The Journal of Physical Chemistry C, vol. 113, no. 47, pp. 20234-20239, 2009.

[19] Q. Li, R. Li, Y. Xing, L. Zong, and J. Yang, "Incorporation of $\mathrm{Sn}^{2+}$ into titanic acid nanotubes and investigation of their visiblelight-responsive photocatalytic activity," Science of Advanced Materials, vol. 5, no. 3, pp. 227-232, 2013.

[20] Y. Xing, R. Li, Q. Li, and J. Yang, "A new method of preparation of $\mathrm{AgBr} / \mathrm{TiO}_{2}$ composites and investigation of their photocatalytic activity," Journal of Nanoparticle Research, vol. 14, no. 12, article 1284, 2012.

[21] J. Yang, Z. Jin, X. Wang et al., "Study on composition, structure and formation process of nanotube $\mathrm{Na}_{2} \mathrm{Ti}_{2} \mathrm{O}_{4}(\mathrm{OH})_{2}$," Journal of the Chemical Society. Dalton Transactions, no. 20, pp. 38983901, 2003.

[22] Q. Y. Li, L. L. Zong, Y. Y. Xing, X. Wang, L. Yu, and J. Yang, "Preparation of g- $\mathrm{C}_{3} \mathrm{~N}_{4} / \mathrm{TiO}_{2}$ nanocomposites and investigation of their photocatalytic activity," Science of Advanced Materials, vol. 5, no. 9, pp. 1316-1322, 2013.

[23] M. Zhang, Z. Jin, J. Zhang et al., "Effect of annealing temperature on morphology, structure and photocatalytic behavior of nanotubed $\mathrm{H}_{2} \mathrm{Ti}_{2} \mathrm{O}_{4}(\mathrm{OH})_{2}$," Journal of Molecular Catalysis A: Chemical, vol. 217, no. 1-2, pp. 203-210, 2004.

[24] M. Nasir, Z. Xi, M. Xing et al., "Study of synergistic effect of Ceand S-codoping on the enhancement of visible-light photocatalytic activity of $\mathrm{TiO}_{2}$," The Journal of Physical Chemistry $C$, vol. 117, no. 18, pp. 9520-9528, 2013. 
[25] H. Liu, M. Wang, Y. Wang, Y. Liang, W. Cao, and Y. Su, "Ionic liquid-templated synthesis of mesoporous $\mathrm{CeO}_{2}-\mathrm{TiO}_{2}$ nanoparticles and their enhanced photocatalytic activities under UV or visible light," Journal of Photochemistry and Photobiology A: Chemistry, vol. 223, no. 2-3, pp. 157-164, 2011.

[26] B. M. Reddy, A. K. Khan, Y. Yamada, T. Kobayashi, S. Loridant, and J.-C. Volta, "Structural characterization of $\mathrm{CeO}_{2}-\mathrm{TiO}_{2}$ and $\mathrm{V}_{2} \mathrm{O}_{5} / \mathrm{CeO}_{2}-\mathrm{TiO}_{2}$ catalysts by Raman and XPS techniques," The Journal of Physical Chemistry B, vol. 107, no. 22, pp. 5162-5167, 2003.

[27] X. Gao, Y. Jiang, Y. Zhong, Z. Luo, and K. Cen, “The activity and characterization of $\mathrm{CeO}_{2}-\mathrm{TiO}_{2}$ catalysts prepared by the solgel method for selective catalytic reduction of $\mathrm{NO}$ with $\mathrm{NH}_{3}$," Journal of Hazardous Materials, vol. 174, no. 1-3, pp. 734-739, 2010.

[28] N. J. Price, J. B. Reitz, R. J. Madix, and E. I. Solomon, "A synchrotron XPS study of the vanadia-titania system as a model for monolayer oxide catalysts," Journal of Electron Spectroscopy and Related Phenomena, vol. 98-99, pp. 257-266, 1999.

[29] J. Fang, X. Bi, D. Si, Z. Jiang, and W. Huang, "Spectroscopic studies of interfacial structures of $\mathrm{CeO}_{2}-\mathrm{TiO}_{2}$ mixed oxides," Applied Surface Science, vol. 253, no. 22, pp. 8952-8961, 2007.

[30] S. K. Parayil, H. S. Kibombo, C. M. Wu et al., "Synthesisdependent oxidation state of platinum on $\mathrm{TiO}_{2}$ and their influences on the solar simulated photocatalytic hydrogen production from water," Journal of Physical Chemistry C, vol. 117, no. 33, pp. 16850-16862, 2013.

[31] S. V. N. T. Kuchibhatla, A. S. Karakoti, D. R. Baer et al., "Influence of aging and environment on nanoparticle chemistry: implication to confinement effects in nanoceria," The Journal of Physical Chemistry C, vol. 116, no. 26, pp. 14108-14114, 2012.

[32] M. Palummo, G. Giorgi, L. Chiodo, A. Rubio, and K. Yamashita, "The nature of radiative transitions in $\mathrm{TiO}_{2}$-based nanosheets," The Journal of Physical Chemistry C, vol. 116, no. 34, pp. 1849518503, 2012.

[33] A. E. Jiménez González and S. Gelover Santiago, "Structural and optoelectronic characterization of $\mathrm{TiO}_{2}$ films prepared using the sol-gel technique," Semiconductor Science and Technology, vol. 22, no. 7, pp. 709-716, 2007.

[34] K. Lv, Q. Xiang, and J. Yu, "Effect of calcination temperature on morphology and photocatalytic activity of anatase $\mathrm{TiO}_{2}$ nanosheets with exposed 001 facets," Applied Catalysis B: Environmental, vol. 104, no. 3-4, pp. 275-281, 2011.

[35] L. C. Liu, Z. Y. Ji, W. X. Zou et al., "In situ loading transition metal oxide clusters on $\mathrm{TiO}_{2}$ nanosheets as co-catalysts for exceptional high photoactivity," ACS Catalysis, vol. 3, no. 9, pp. 2052-2061, 2013. 

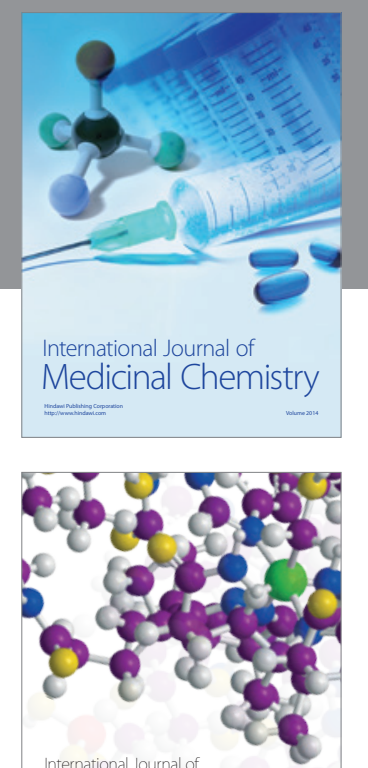

\section{Carbohydrate} Chemistry

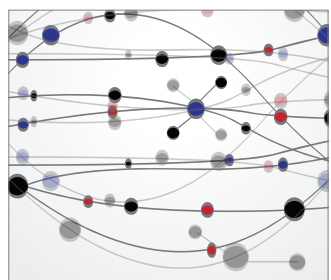

The Scientific World Journal
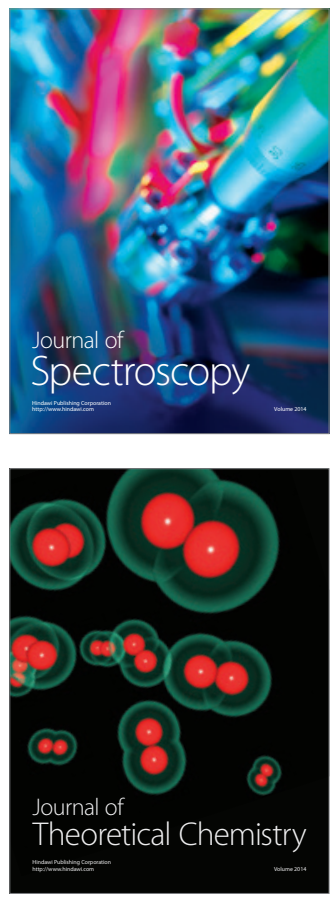
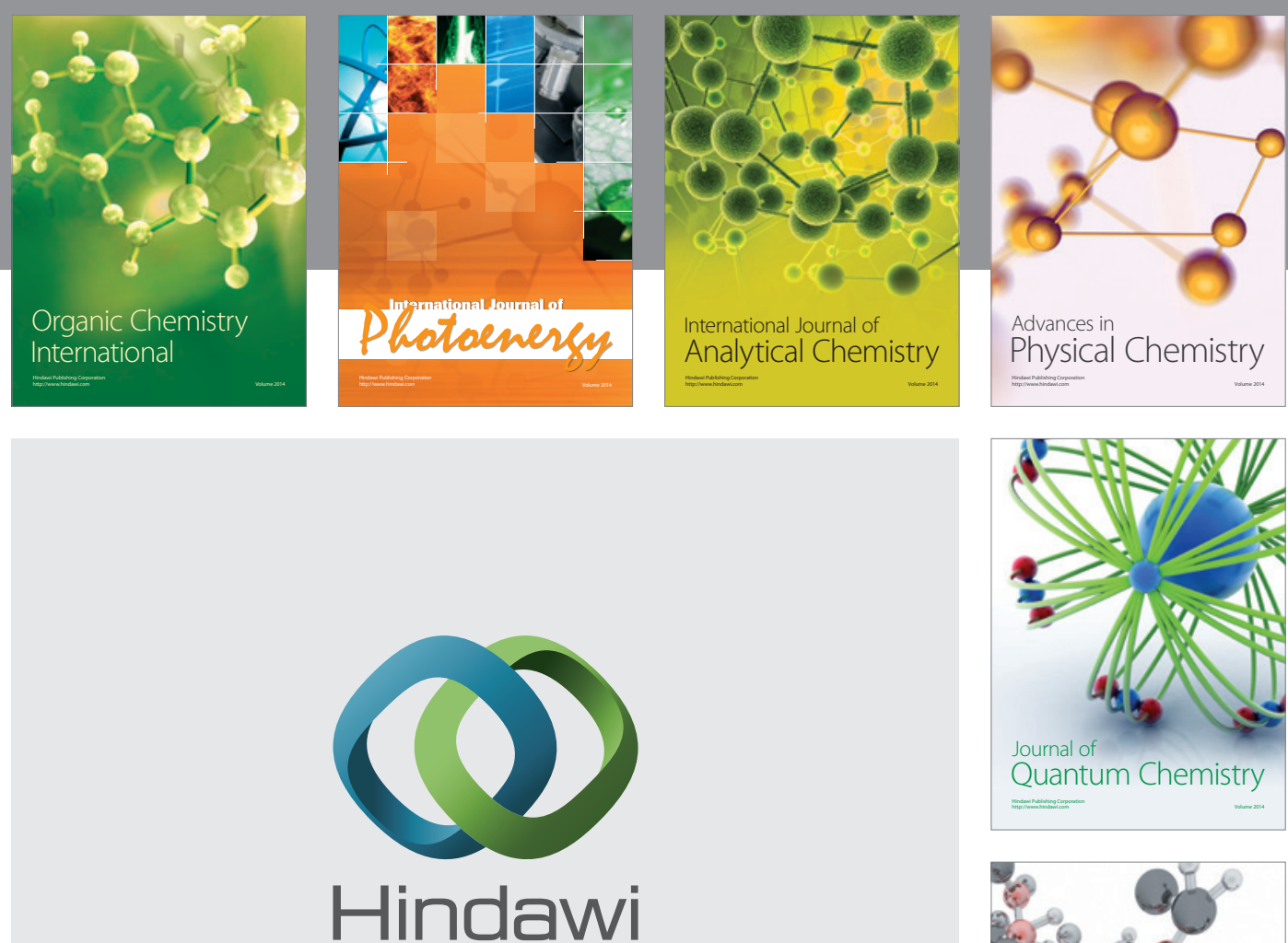

Submit your manuscripts at

http://www.hindawi.com

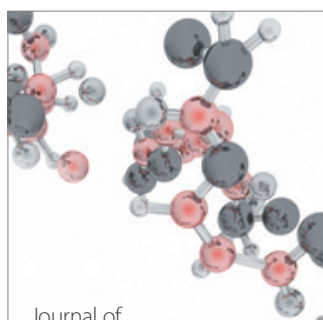

Analytical Methods

in Chemistry

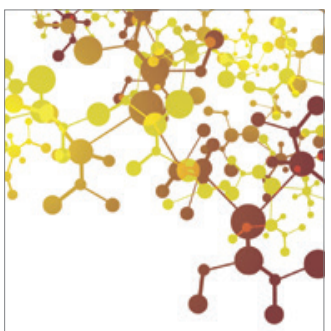

Journal of

Applied Chemistry

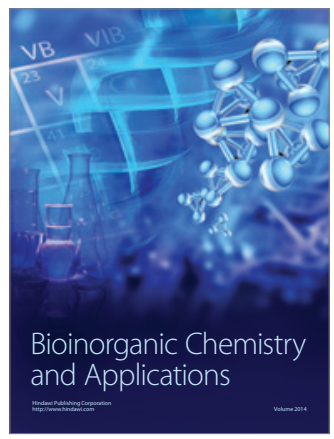

Inorganic Chemistry
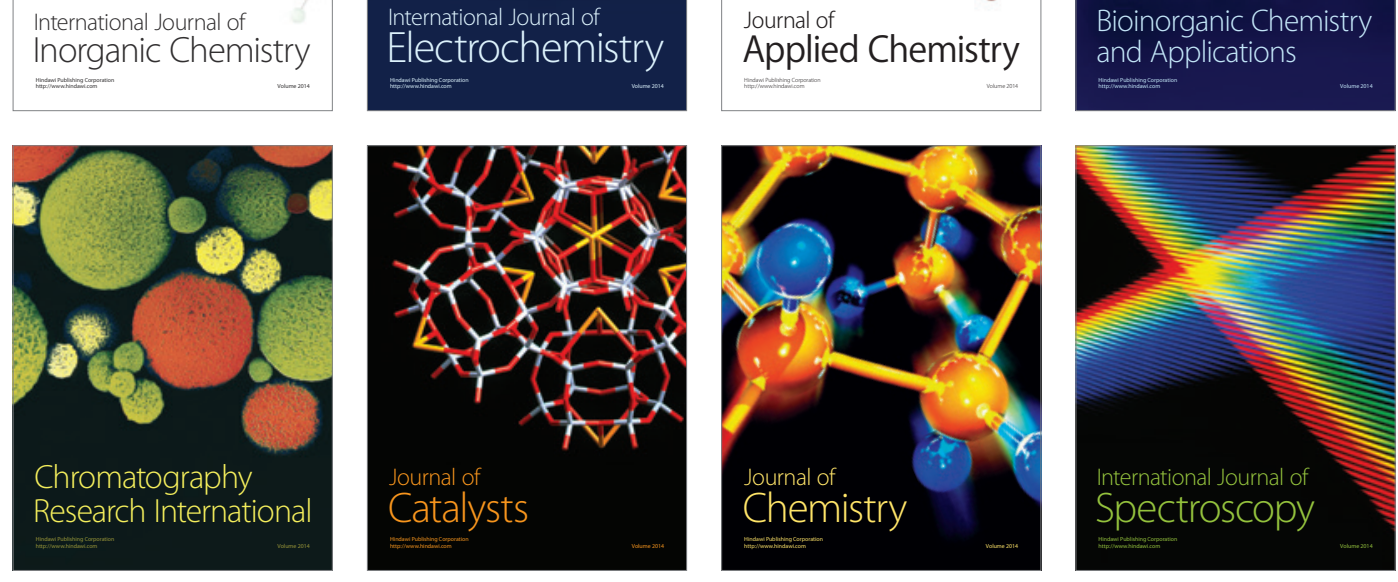